\title{
The use of noninvasive mechanical ventilation for the treatment of acute exacerbations of chronic obstructive pulmonary disease in Canada
}

\author{
Jennifer Drummond $\mathrm{RRT}^{1}$, Brian Rowe MD MSc${ }^{2}$, Lawrence Cheung MD ${ }^{1}$, Irvin Mayers MD ${ }^{1}$
}

\begin{abstract}
J Drummond, B Rowe, L Cheung, I Mayers. The use of noninvasive mechanical ventilation for the treatment of acute exacerbations of chronic obstructive pulmonary disease in Canada. Can Respir J 2005;12(3):129-133.
\end{abstract}

BACKGROUND: Noninvasive mechanical ventilation (NIMV) is accepted as a life-saving treatment for patients presenting to the emergency department and other acute care settings with severe exacerbations of chronic obstructive pulmonary disease (COPD).

OBJECTIVES: It was hypothesized that there is marked national variability in the use of NIMV. Therefore, the use of NIMV for COPD exacerbations in urban centres across Canada was evaluated.

METHODS: All Canadian hospitals affiliated with a university training program were surveyed, and a request for involvement in this survey was posted on the Canadian Society of Respiratory Therapy professional practice listserv. Survey information was received from all 33 sites (100\%) that were contacted.

RESULTS: Marked differences in the application of NIMV were identified across all regions in Canada, ranging from requiring extensive monitoring in the intensive care unit to application on a general internal medical unit with intermittent noninvasive blood pressure monitoring. There were sites that rarely used NIMV for COPD exacerbations and others where it was routine practice.

CONCLUSIONS: NIMV is a life-saving treatment for acute exacerbations of COPD. Despite clear clinical evidence, its use has not penetrated throughout all the larger urban hospitals in Canada. This may be more problematic in sites without $24 \mathrm{~h}$ respiratory therapy support. There are barriers to the routine application of NIMV that can be overcome using established guidelines and available evidence.

Key Words: COPD; Exacerbation; Mechanical ventilation; Noninvasive

C ranada, along with most other regions in the world, is in the midst of an epidemic of hospitalization and death from chronic obstructive pulmonary disease (COPD). Hospitalizations for acute exacerbations of COPD in Canada reached 60,000 individuals in 2001 and are anticipated to increase to nearly 120,000 individuals by the year 2015 (1). The associated mortality has ranged from nearly 12,000 deaths in 2001 to an anticipated 20,000 in 2015. Given the chronic decline in respiratory function associated with COPD and the aging population, an increasing number of patients with severe COPD will be occupying beds in emergency departments (ED), intensive care units (ICU) and hospitals over the next decade.

Treatment for the majority of patients with an acute exacerbation of COPD has traditionally included controlled oxygen, selective antibiotics, beta-agonist with or without anticholinergic
La ventilation artificielle non effractive et le traitement des exacerbations de bronchopneumopathie chronique obstructive au Canada

CONTEXTE : La ventilation artificielle non effractive (VANE) est reconnue comme un traitement salvateur des exacerbations graves de bronchopneumopathie chronique obstructive (BPCO) dans les services d'urgence et dans d'autres services de soins actifs.

OBJECTIF : Selon certaines hypothèses, l'utilisation de la VANE varierait énormément d'une région à l'autre au Canada. La présente étude visait donc à évaluer le recours à la VANE pour les exacerbations de $\mathrm{BPCO}$, dans les centres urbains, partout au Canada.

MÉTHODE : Tous les hôpitaux canadiens affiliés à un programme universitaire de formation ont participé à l'enquête, et une demande en ce sens a été adressée à partir du serveur de liste de la Société canadienne des thérapeutes respiratoires. Les 33 centres (100 \%) avec lesquels nous avions communiqué ont fourni des données.

RÉSULTATS : Des différences marquées ont été relevées quant à l'emploi de la VANE dans toutes les régions du Canada; les écarts variaient d'une surveillance étroite en service de soins intensifs à une utilisation plus souple dans des services de médecine interne générale, accompagnée d'une surveillance non effractive et intermittente de la pression artérielle. Dans certains établissements, on recourait rarement à la VANE dans les cas d'exacerbation de BPCO, tandis que dans d'autres c'était pratique courante. CONCLUSION : La VANE est un traitement salvateur des exacerbations de BPCO. Malgré des données cliniques probantes, son emploi n’a pas trouvé écho dans tous les grands hôpitaux des centres urbains au Canada. La situation peut se révéler problématique dans les établissements dépourvus d'un service d'inhalothérapie 24 heures sur 24. Cependant, des lignes directrices clairement définies et des preuves à l'appui pourraient venir à bout de certains obstacles à l'utilisation courante de la VANE.

bronchodilators and systemic corticosteroids. For some patients, this approach has been insufficient to avoid hospitalization; a recent study (2) across many North American EDs showed a $59 \%$ admission rate. For other patients, even aggressive and evidence-based management in the ED is insufficient to prevent further deterioration, intubation or death.

Over the past decade, the use of noninvasive mechanical ventilation (NIMV) has been shown to markedly improve in-hospital outcomes $(3,4)$. For example, NIMV in acute COPD has been shown to result in decreased mortality (RR 0.41; 95\% CI 0.26 to 0.64 ), fewer intubations (RR 0.42; 95\% CI 0.31 to 0.59 ) and fewer treatment failures (RR $0.51 ; 95 \%$ CI 0.39 to 0.67) $(3,4)$. Common complications associated with treatment (RR $0.32 ; 95 \%$ CI 0.18 to 0.56 ) and length of hospital stay (mean difference -3.24 days; $95 \%$ CI -4.42 to -2.06 ) were also

${ }^{1}$ Department of Medicine; ${ }^{2}$ Division of Emergency Medicine, University of Alberta, Edmonton, Alberta

Correspondence and reprints: Dr Irvin Mayers, Department of Medicine, Room 2E4.38 Walter C MacKenzie, Edmonton, Alberta T6G $2 B 7$.

Telephone 780-407-1854, fax 780-407-6384, e-mail imayers@ualberta.ca 
reduced in the NIMV group. The use of NIMV in the ED could reduce ICU admissions from $74 \%$ to $26 \%$ (5).

The use of NIMV in the treatment of an acute exacerbation of COPD is now supported by evidence-based guidelines $(6,7)$. There is consensus that NIMV does not offer significant benefit for patients with mild exacerbations or for those receiving delayed treatment ( $24 \mathrm{~h}$ to $48 \mathrm{~h}$ after admission) (8). However, there remain many controversial topics, including the optimal hospital location for ongoing NIMV therapy (eg, general ward, specialized care setting, step-down unit or ICU); the use of NIMV in patients who decline endotracheal intubation; or even which physician groups should be directing the delivery of this treatment (eg, family physician, internist, pulmonologist or intensivist). NIMV treatment is now a decade into general acceptance in the medical literature, yet consensus on these issues has not been developed. We hypothesized that practice variation exists regarding the availability and the use of NIMV in acute COPD within the larger, urban hospitals in Canada. We surveyed both teaching and community hospitals in the majority of urban centres to determine how NIMV is applied in Canada.

\section{METHODS}

\section{Survey}

A two-page survey was developed by the research team to determine the use, limitations and systems of NIMV applied in patients with acute COPD in Canada. The questions posed were related to patterns and practices of NIMV use in urban hospitals in Canada.

\section{Survey sampling}

Between February 2004 and May 2004, 34 centres were surveyed across Canada regarding their use of NIMV. Initially, all sites affiliated with a medical school pulmonary training program were contacted. Subsequently, a request for participation was posted on the Canadian Society of Respiratory Therapy Web site. The survey was arbitrarily restricted to hospitals with a bed capacity exceeding 200 acute care beds, thereby, reducing the sample to 33 centres.

Hospitals from every province in Canada were surveyed and categorized to represent the Maritimes, Quebec, Ontario, western Canada and British Columbia regions in Canada. Northern centres were not surveyed; therefore, the Canadian territories are not represented in the findings. Physicians (pulmonary or critical care training directors) and/or respiratory therapists (professional practice leaders, educators or managers) were contacted at each site. A total of 33 sites were approached by e-mail, fax and telephone to complete the survey on NIMV use in acute COPD. Following a maximum of three attempts, one completed survey was collected from each site. In 29 sites, the respondents were respiratory therapists (as described above); in one site, the respondent was a physician; and in three sites both respiratory therapists and physicians responded. Only one reply from each site was received from each site. Question 7 (the use of NIMV in end-of-life care) was surveyed separately at a later point, and only 25 (76\%) of 33 sites responded.

\section{Statistics}

Simple descriptive statistics are presented.

\section{RESULTS}

\section{Response rate}

From the 33 sites with more than 200 beds that were surveyed, all (100\%) responded by completing a questionnaire.

\section{Use of NIMV}

Table 1 outlines the regional variability in NIMV use. Despite its proven clinical effectiveness at reducing in-hospital mortality, this is a standard of care in only one-half of the surveyed sites. Although current guidelines (7) strongly recommend that NIMV treatment be initiated early in the ED setting, there were centres in each region that did not do so. The majority $(70 \%)$ of centres currently restrict NIMV outside of the ED to an ICU setting or to step-down units. This is consistent with the responses that indicated the majority of sites use some form of continuous cardiopulmonary monitoring, up to and including invasive blood pressure monitoring. However, there was still a significant minority of sites (18\%) in most regions that would administer NIMV on general medical wards with minimal cardiopulmonary monitoring. There were eight sites that treated two or fewer patients per month with NIMV. The use of NIMV in patients with advanced directives or with limitations set on treatment also varied significantly across the country. In the setting of a "do not intubate" or "no CPR" (cardiopulmonary resuscitation) order, 32\% would not or rarely initiate NIMV therapy. A similar number would not use or rarely use NIMV for palliative purposes.

\section{Mechanics}

There are marked differences in the types of airflow generators used to deliver this form of mechanical ventilation in Canada. These range from machines that are typically used in the chronic home setting for stable patients to ventilators typically restricted to an ICU setting only. A commonly used machine, Vision (Respironics, USA), falls somewhere between these two extremes. The interface used to administer the flow, the nasal or oronasal masks, also varied markedly among the sites.

\section{DISCUSSION}

There are several limitations to the present study. The reliability of the data collection was not specifically tested; however, we do believe these data were subject to marked error. The individuals responding to the questionnaires were directly responsible for NIMV use and would be aware of these details, and there was variability among sites as to who provided the data. Second, the data have not been independently validated. In some cases, the information required the recall of trends over several months (eg, numbers of patients treated per month). However, this survey was meant to examine the broad trends in the application of NIMV; therefore, we completed only descriptive analyses. Finally, the sample also did not include some larger nonteaching hospitals where NIMV use may be occurring. However, this sample represents large urban teaching and academic centres, and should be representative of practice in these settings.

This survey of academic and large teaching hospitals across Canada failed to identify clear standards for the use of NIMV therapy. There is wide practice variation among sites which cannot be explained by hospital size, region of the country or academic affiliation. Each centre appears to have developed an individualized approach to the delivery of this important and often life-saving treatment. Overall, nearly $30 \%$ of sites restrict NIMV to ICU settings only, and a further 12 (36\%) sites only permit NIMV use in step-down or ICU settings. We are concerned that the current dependence on ICUs for the delivery of NIMV will limit this life-saving therapy to those patients 
TABLE 1

Regional variation in the use of noninvasive mechanical ventilation (NIMV)

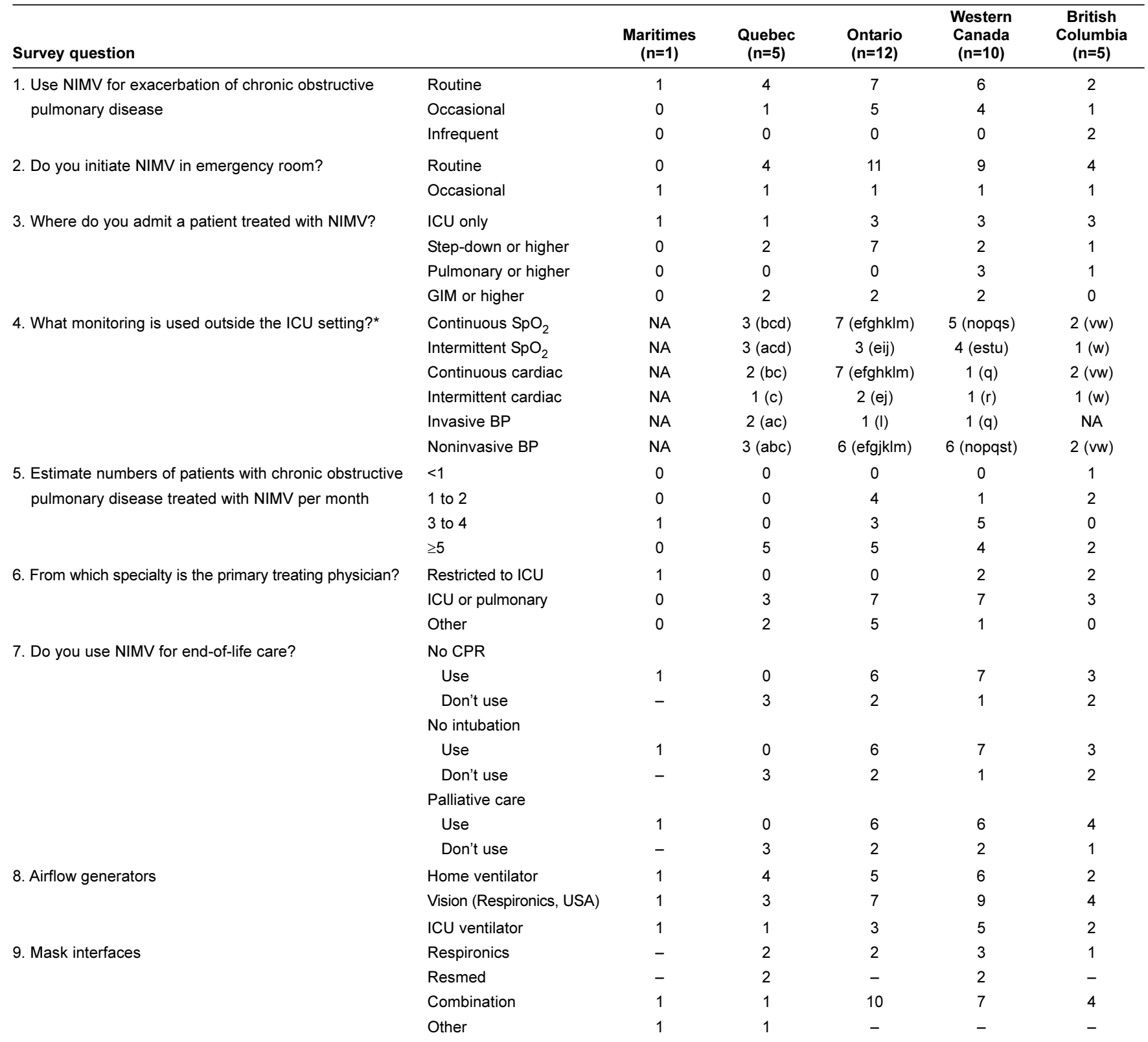

*Note in question 4, NA (Not applicable) and each regional site (in parenthesis) is denoted by a unique letter because each site may use more than one modality of monitoring. Continuous cardiac Continuous electrocardiograph monitoring; CPR Cardiopulmonary resuscitation; ICU Intensive care unit; Invasive BP Intra-arterial blood pressure monitoring; GIM General internal medicine; Noninvasive BP Continuous automated blood pressure monitoring; SpO ${ }_{2}$ Oxygen saturation by pulse oximetry

least likely to reap significant benefit (eg, those with severe disease). The chronic shortage of ICU beds may make it virtually impossible for all patients with COPD who might benefit from therapy to receive it. Other alternatives must be explored.

We are also concerned that the reliance on ICUs for this therapy will preclude its use in patients who do not wish to be intubated or resuscitated. This is highlighted by our finding that this treatment is rarely or not offered to patients who do not wish to have traditional ICU therapies that include cardiopulmonary resuscitation or intubation. The majority of the responding sites, even if they did use NIMV for patients with "do not resuscitate" or "do not intubate" orders, often added descriptors when replying to this question (eg, "we do not advocate it", "only if reversible within 24 hours" and "sometimes, but not often"). There was a clear reluctance on the part of most of the centres surveyed to routinely apply NIMV to patients who wish to limit the extremes of possible hospital care. To our knowledge, there are no studies that have examined the outcomes of patients who wish to limit care, which is an important area for exploration.

The benefits of NIMV for patients with an acute exacerbation of COPD are now clearly described in the medical literature. The reduction of in-hospital mortality has been shown in many well-designed, randomized controlled trials. A recent systematic review (3) confirmed the effectiveness of NIMV treatment in reducing in-hospital mortality in severe exacerbations. The authors additionally reviewed two studies in which patients with milder exacerbations were started on NIMV after 


\section{TABLE 2 \\ Proposed inclusion and exclusion criteria for admission to a pulmonary-based noninvasive mechanical ventilation (NIMV) ward}

\section{Inclusion criteria}

- Patients admitted as an emergency with an acute exacerbation of chronic obstructive pulmonary disease (on the basis of the clinical history, physical examination and chest radiograph

- Tachypnea with a respiratory rate of more than 25 breaths/min

- $\mathrm{pH}<7.35$ with a $\mathrm{PaCO}_{2}>45 \mathrm{mmHg}$ on arrival to emergency department (arterial gases taken within $1 \mathrm{~h}$ )

- Dyspnea noted on clinical assessment of accessory muscle use, abdominal paradoxical respirations and/or patient confirmation of dyspnea

- Time in emergency department (elapsed time from registration to patient being assessed for NIMV) within a maximum of $12 \mathrm{~h}$

- The patient must be able and willing to cooperate with medical treatment

Exclusion criteria

- A requirement for emergency intubation for cardiopulmonary resuscitation or as a result of respiratory arrest or a rapid deterioration in neurological status

- Hemodynamic instability, defined as a systolic blood pressure $<80 \mathrm{mmHg}$ or evidence on electrocardiogram of ischemia or clinically significant ventricular arrhythmias

- Respiratory failure not primarily due to chronic obstructive pulmonary disease, eg, pneumonia or congestive heart failure, as established by physical signs and findings on chest $\mathrm{x}$-ray films and echocardiograms

- Recent failure of more than two organs excluding pulmonary

- Presence of a tracheotomy

- Facial deformity preventing application of a nasal or full face mask

- Untreated pneumothorax

$\mathrm{PaCO}_{2}$ Pressure of carbon dioxide in arterial blood

transfer from the ED to a ward setting. In these patients with milder exacerbations, NIMV treatment was significantly delayed and those started on NIMV after transfer from the ED to a ward setting failed to demonstrate a measurable benefit. However, delaying treatment will select a group that will not receive benefit (eg, they will either deteriorate and not be included or will improve and not need treatment). Until there are clear physiological or biochemical parameters that can be used to distinguish responders from nonresponders, it is difficult to be overly dogmatic concerning which patients with an exacerbation of COPD should or should not receive NIMV in the ED setting. It is worthwhile comparing COPD treatment with another common ED-treated disease such as acute myocardial infarction, where achieving an absolute reduction of $1.1 \%$ in-hospital mortality is considered to be a worthwhile and commendable achievement (9). It is clear that there is a major mortality benefit in treating severe exacerbations of COPD with NIMV. However, from the relatively small studies to date, it is not clear that NIMV will not yield a clinically significant mortality benefit in milder exacerbations of COPD.

Complementary to the findings from randomized controlled trials is a recent prospective cohort study of NIMV use (10). The findings were consistent with results from NIMV trials demonstrating reduced deaths in patients treated with NIMV compared with mechanical ventilation via an endotracheal tube. This reduction was primarily due to decreased nosocomial infections, a common complication of endotracheal intubation. These findings are consistent with other observations that patients with acute lung injury treated by NIMV demonstrated fewer nosocomial infections than those treated by intubation (11). Girou et al (10) also noted a significant learning effect, with mortality decreasing over the eight-year period of their study. This raises some concerns with the delivery of NIMV at many sites in Canada. We, in fact, found that eight sites used NIMV on two or fewer patients per month. With such infrequent usage, the sites may not achieve the threshold needed to become expert at NIMV application. This also raises concerns that health care teams outside of EDs or of specialized care units may not receive sufficient experience to overcome the learning effect.

There is also considerable controversy regarding the appropriate location to deliver NIMV therapy. All the studies to date support the idea that NIMV should be initiated early in the course of respiratory failure; in North America, that would mean it should be initiated following assessment in the ED. A recent evidence-based review of COPD by the Canadian Thoracic Society (CTS) (7) recommended that NIMV therapy should be administered only in a setting with close cardiopulmonary monitoring (level of evidence 2B). Based on these survey results, this recommendation is being followed in most Canadian centres. Continuous monitoring of cardiopulmonary parameters during delivery of NIMV is generally a standard of care in the ED; however, the rationale for extending this recommendation to sites outside the ED is not clear. We agree that patients receiving NIMV are at significant risk for needing intubation and demand close observation; however, patients with COPD who are not receiving NIMV are in fact at higher risk for needing intubation and yet are routinely managed in low-intensity ward settings with just routine monitoring of vital signs. Moreover, there is no evidence that routine use of continuous pulse oximetry alters clinically important outcomes outside of the operating room or invasive interventional settings (12). Similarly, the rationale for continuous electrocardiograph monitoring is not evidence-based because the majority of in-patients who die from acute COPD develop worsened respiratory failure, not an acute malignant arrhythmia. In a retrospective study, Sinuff et al (13) found that there was a mean of $3.0 \mathrm{~h}$ between the initiation of NIMV and intubation in patients who progressed to need intubation. None of the patients with COPD experienced a myocardial infarction before intubation. A more recent review (14) examining the optimal location and monitoring needs for patients receiving NIMV concluded that there was no evidence to support the need for an ICU setting. The authors believed that the training and familiarity of staff with the procedure were important factors in deciding where to deliver care.

Using these recommendations as well as those from the British Thoracic Society (6), we have developed a set of practical criteria to determine who may be safely treated on a pulmonary ward setting (Table 2). These criteria are similar to the inclusion and exclusion criteria used by the two largest published randomized, controlled trials $(4,5)$. These clinical trials used the need for intubation as a primary end point and, therefore, excluded patients who were not willing to undergo intubation. However, we do not believe that this is a valid reason to continue to exclude this population from receiving NIMV and therefore, our proposed clinical criteria do not exclude these 
patients. Table 2 also very closely follows the recent guidelines from the CTS (7). However, the CTS recommendations also include the need for admission to a hospital location with the capacity for close cardiopulmonary monitoring. From a practical perspective, these are issues that must be addressed. The British Thoracic Society guidelines (6) and the study by Girou et al (10) strongly suggest that a dedicated unit be developed with expertise in NIMV to ensure the safe and effective delivery of care. It is unlikely that these recommendations will ever be subjected to a randomized controlled trial evaluation. In the current climate of scarce ICU resources, it would be nearly impossible to implement such a study. Instead, there is a need for rational therapy based on the best available evidence. Trials designed to evaluate these delivery issues should be developed to ensure that these treatments are broadly available but safely delivered.

From a research perspective, there is also a need for ongoing, prospective evaluation of the outcomes of the various approaches to help guide future improvements in the effective delivery of care. This survey suggests that there are significant and important clinical practice variations in the care offered to patients arriving in the $\mathrm{ED}$ with an exacerbation of COPD. There is currently sufficient clinical evidence to develop consistent treatment plans without more randomized controlled trials. It has taken a decade to realize that NIMV should be better applied across Canadian hospitals. This problem will only get worse in the future as the number of patients hospitalized with COPD is expected to double over the next decade.

FUNDING: This project was supported, in part, by a program grant from the Alberta Health Innovation Fund. The project was also partially supported by a program grant provided by the Medical Services Branch of Alberta Health and Wellness, and the Alberta Medical Association. Dr Rowe's research is supported by the Canadian Institute of Health Research as a Canada Research Chair.

\section{REFERENCES}

1. Canadian Institutes for Health Research. Respiratory Disease in Canada. Ottawa: Health Canada, 2001.

2. Cydulka RK, Rowe BH, Clark S, Emerman CL, Camargo CA Jr; MARC Investigators. Emergency department management of acute exacerbations of chronic obstructive pulmonary disease: The Multicenter Airway Research Collaboration. J Am Geriatr Soc 2003;51:908-16.

3. Ram FS, Picot J, Lightowler J, Wedzicha JA. Non-invasive positive pressure ventilation for treatment of respiratory failure due to exacerbations of chronic obstructive pulmonary disease. Cochrane Database Syst Rev 2004;(3):CD004104.

4. Plant PK, Owen JL, Elliott MW. Early use of non-invasive ventilation for acute exacerbations of chronic obstructive pulmonary disease on general respiratory wards: A multicentre randomised controlled trial. Lancet 2000;355:1931-5.

5. Brochard L, Mancebo J, Wysocki M, et al. Noninvasive ventilation for acute exacerbations of chronic obstructive pulmonary disease. N Engl J Med 1995;333:817-22.

6. British Thoracic Society Standards of Care Committee. Noninvasive ventilation in acute respiratory failure. British Thoracic Society Standards of Care Committee. Thorax 2002;57:192-211.

7. O'Donnell DE, Aaron S, Bourbeau J, et al; Canadian Thoracic Society. Canadian Thoracic Society recommendations for management of chronic obstructive pulmonary disease - 2003 . Can Respir J 2003;10(Suppl A):11A-65A.
ACKNOWLEDGEMENT: The authors would like to thank all the centres that participated in this survey. British Columbia: St Pauls Hospital, Rennie London RRT; Vancouver General Hospital, Ron Thiessen RRT; Surrey Memorial, Lakh Bagri RRT; Royal Columbian, Rose Pagnotta RRT; Lion's Gate, Vern Guimond RRT. Western Canada: University of Alberta, Dr L Cheung, Jennifer Drummond RRT; Royal Alexandra, Dr B Murtha, John Alberta RRT; Grey Nuns, Mike Krause RRT; Misericordia, Cheryl Babiak RRT; Calgary Health Region, Greg Duchscherer RRT; David Thomspson Health Region, Shawna Demas RRT; Peter Lougheed Hospital, George Handley RRT; Royal University Hospital, Doug Ellingsen RRT; Regina Qu'Appelle Health Region, Brent Kitchen RRT; North Battleford, Craig Hillier RRT; University of Manitoba, Dr Steven Mink; Ontario: St Josephs, Dr Rob Mcfadden, Ginny Martins RRT; St Michaels, Brent West RRT; Kingston General Hospital, Dr M Fitzpatrick, Cynthia Phillips RRT, Sandy Fodey RRT; Ottawa Hospital, Julie Boulianne RRT; Toronto University Health Network, Sandra Grgas RRT; Toronto Sunnybrook and Womens Hospital, Gary Akerman RRT; Toronto East General, Nancee Prescott RRT; Hamilton Health Sciences Center, Gemini Toprani RRT; London Health Sciences Centre, Chris Harris RRT; Humber River Regional Hospital, Marg Patell RRT; Quebec: CH Maisonneuve Rosemont, Mario Dumaresq RRT; Hopital Laval, M Jean-Eudes Bonenfant RRT; Centre Universitaire de Sante de L'Estrie, Paulette Robitaille RRT; Montreal Chest Hospital, Nancy Fong RRT. Maritimes: Atlantic Health Services Corporation, Kelly Mason RRT; Healthcare Corporation St Johns, Rick Halfyard RRT.

DISCLOSURE: Dr Rowe has received research support and speaking fees from GlaxoSmithKline, AstraZeneca, BoehringerIngelheim and Trudell-Monahan. He is not a paid consultant for any of these companies, nor any company that manufactures noninvasive mechanival ventilation equipment. Dr Mayers has received research support and speaking fees from GlaxoSmithKline, Eli Lilly, AstraZeneca, Boehringer-Ingelheim, Aventis Pharma and Altana. He does not receive any financial support from any companies that manufacture noninvasive mechanival ventilation equipment.

8. Keenan SP, Sinuff T, Cook DJ, Hill NS. Which patients with acute exacerbation of chronic obstructive pulmonary disease benefit from noninvasive positive-pressure ventilation? A systematic review of the literature. Ann Intern Med 2003;138:861-70

9. Mark DB, Hlatky MA, Califf RM, et al. Cost effectiveness of thrombolytic therapy with tissue plasminogen activator as compared with streptokinase for acute myocardial infarction N Engl J Med 1995;332:1418-24. Erratum in 1995;333:267.

10. Girou E, Brun-Buisson C, Taillé S, Lemaire F, Brochard L. Secular trends in nosocomial infections and mortality associated with noninvasive ventilation in patients with exacerbation of COPD and pulmonary edema. JAMA 2003;290:2985-91.

11. Antonelli M, Conti G, Rocco M, et al. A comparison of noninvasive positive-pressure ventilation and conventional mechanical ventilation in patients with acute respiratory failure $\mathrm{N}$ Engl J Med 1998;339:429-35.

12. Bowton DL, Scuderi PE, Harris L, Haponik EF. Pulse oximetry monitoring outside the intensive care unit: Progress or problem? Ann Intl Med 1991;115:450-4

13. Sinuff T, Cook D, Randall J, Allen C. Noninvasive positive-pressure ventilation: A utilization review of use in a teaching hospital. CMAJ 2000;163:969-73

14. Elliott MW, Confalonieri M, Nava S. Where to perform noninvasive ventilation? Eur Respir J 2002;19:1159-66. 


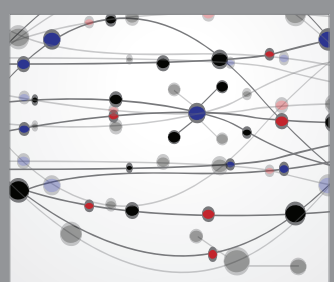

The Scientific World Journal
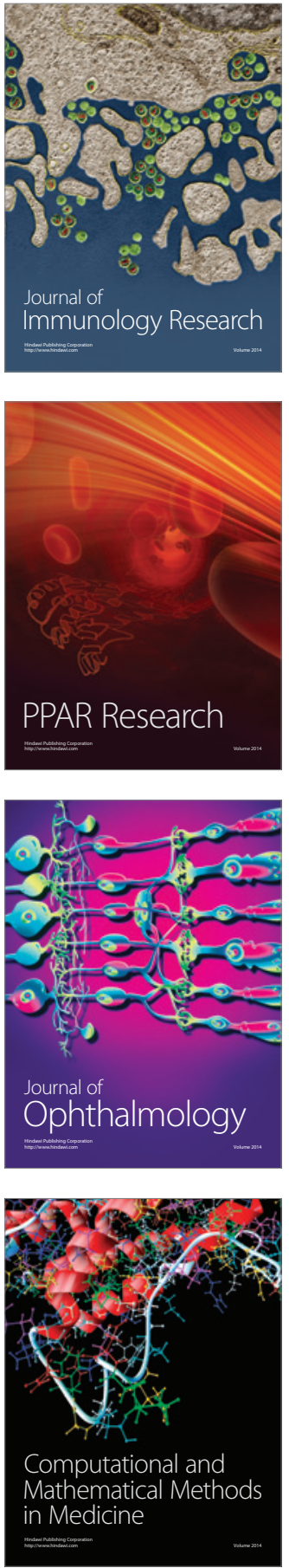

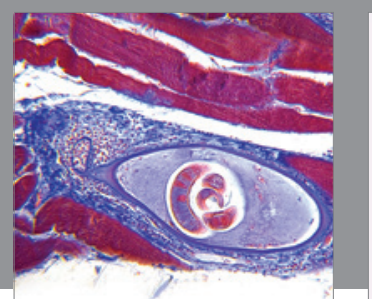

Gastroenterology Research and Practice

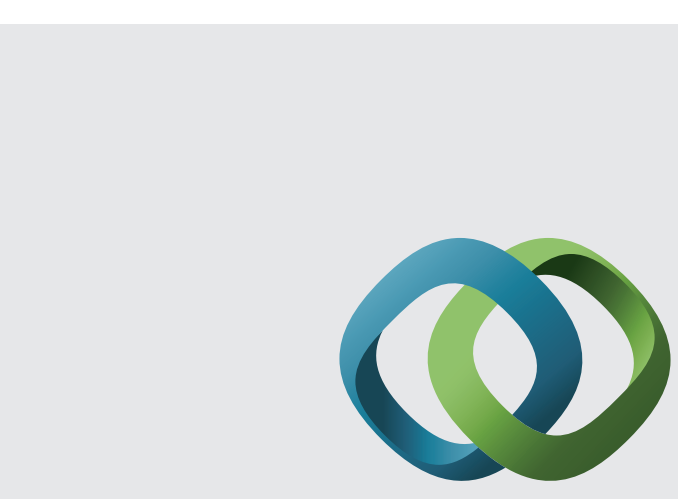

\section{Hindawi}

Submit your manuscripts at

http://www.hindawi.com
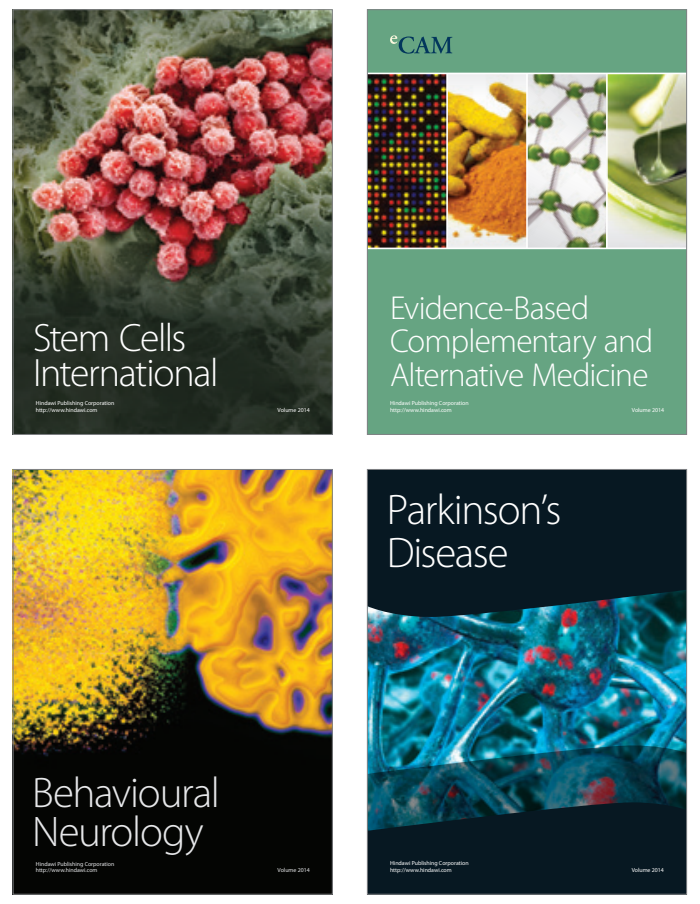
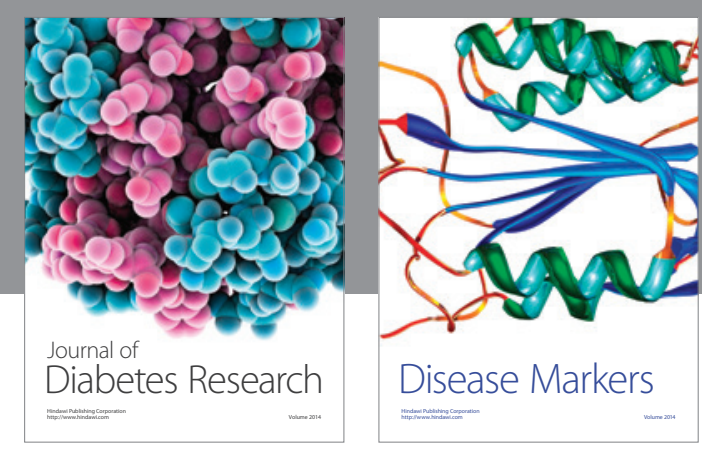

Disease Markers
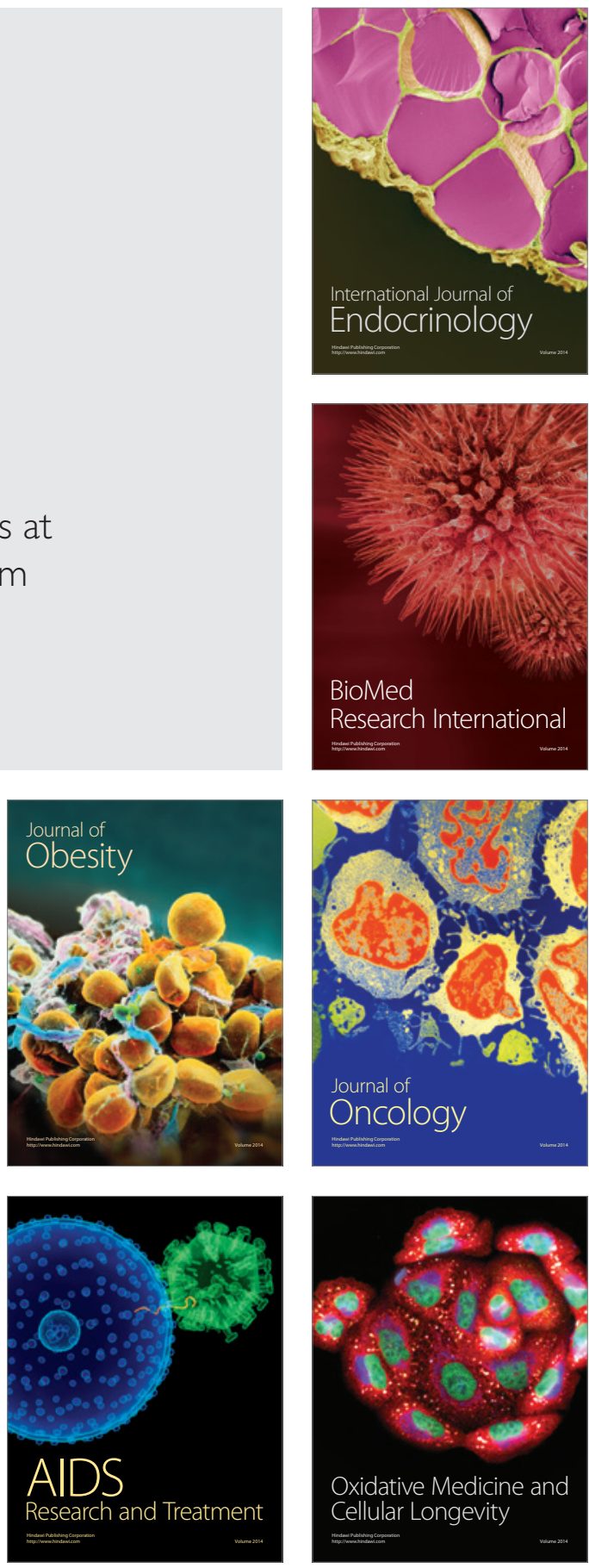